\title{
MENYIASATI PENYEMPITAN MUSIM TANAM PADI DENGAN BUDIDAYA RATUN DAN SALIBU
}

\section{Overcome Limited Growing Season with Cultivation Ratoon and Salibu}

\author{
Marsid Jahari dan Parlin H. Sinaga ${ }^{1)}$ \\ Balai Pengkajian Teknologi Pertanian Riau \\ Jl. Kaharudin Nasution No. 341 Pekanbaru \\ ${ }^{1)}$ Kontributor Utama, email: parlinhs@ yahoo.com
}

\begin{abstract}
One method that can be done to save time during the growing season due to climate change is the cultivation of ratoon or salibu. The study was conducted in Pelalawan Regency in July-October 2014 and in Kapuas Regency in December 2012-August 2013. The purpose of the study was to determine the response of rice lines in the ratoon and salibu cultivation system in tidal land. The study was designed according to randomized completely block design which was repeated three times. The results showed that the cultivation of salibu method in flooding tidal land did not produce grain, whereas in tidal land overflows type $\mathrm{C}$ that water could be regulated, lines P1D-KK-A26, P1D-KKA48b, and P5E-KK-A5 gave yields of salibu more than $4 \mathrm{t} \mathrm{ha}^{-1}$ DMG. Cultivation of rice ratoon can be carried out in flooded or regulated water. Lines P1F-B-A15, P1D-KK-A26, P1D-KK-A45, P1DKK-A48b, P1D-KK-A67, and P5E-KK-A5 can be cultivated both ratoon and salibu. Efforts to anticipate the limited of growing season with the cultivation technique of ratoon can be carried out on tidal land that is dry or flooding, while the salibu technique is good carried out on land that is not always flooded.
\end{abstract}

Kata kunci: Ratun, Salibu, Tidal land, Rice, Growing season

\begin{abstract}
ABSTRAK
Salah satu cara yang dapat dilakukan untuk menghemat waktu musim tanam akibat perubahan iklim adalah budidaya ratun atau salibu. Penelitian dilaksanakan di Kabupaten Pelalawan pada bulan Juli-Oktober 2014 dan di Kabupaten Kapuas Desember 2012-Agustus 2013. Tujuan penelitian adalah mengetahui respon galur-galur padi pada sistem budidaya ratun dan salibu di lahan pasang surut tipe C. Penelitian dirancang menurut rancangan acak kelompok lengkap yang diulang tiga kali. Hasil penelitian menunjukkan bahwa Budidaya padi salibu di lahan pasang surut yang tergenang tidak menghasilkan gabah sedangkan di lahan tipe c yang airnya dapat diatur, galur P1D-KK-A26, P1DKK-A48b, dan P5E-KK-A5 memberikan hasil salibu lebih dari $4 \mathrm{t} \mathrm{ha}^{-1}$ GKG. Budidaya padi ratun dapat dilakukan di lahan yang tergenang maupun yang airnya dapat diatur. Galur P1F-B-A15, P1DKK-A26, P1D-KK-A45, P1D-KK-A48b, P1D-KK-A67, dan P5E-KK-A5 dapat dibudidayakan secara ratun maupun salibu. Upaya menyiasati penyempitan musim tanam dengan teknik budidaya ratun dapat dilaksanakan pada lahan pasang surut yang kering maupun tergenang, sedangkan teknik salibu baik dilaksanakan di lahan yang tidak selalu tergenang.
\end{abstract}

Kata kunci: Ratun, Salibu, Pasang surut, padi, musim tanam

\section{PENDAHULUAN}

Perubahan iklim telah menyebabkan perubahan yang mendasar pada usahatani tanaman padi beberapa tahun terakhir. Pergeseran musim tanam terjadi hampir di semua sentra padi nasional. Pada tahun 2015 musim tanam bergeser 1-3 bulan. Pergeseran musim tanam menyebabkan penyempitan musim tanam. Hal ini diduga akan berlangsung lama hingga terjadi keseimbnagan baru akibat perubahan iklim. Pengaruh pergeseran musim sangat terasa di beberapa wilayah Provinsi Riau seperti: Kabupaten Siak, Bengkalis, dan Pelalawa. Pergeseran musim hujan menyebabkan musim tanam berkurang. 
Penanaman pada musim tanam April-September tidak dapat dilaksanakan karena kemarau panjang dan musim tanam Oktober-Maret bergeser menjadi November-Maret.

Perubahan iklim berdampak terhadap ketidakpastian usahatani karena terancam kekeringan atau banjir. Perubahan iklim berdampak terhadap penurunan hujan musiman pada bulan Juni, Juli, Agustus secara signifikan di sebagian besar wilayah Jawa, Papua, bagian barat Sumatera, dan bagian timur selatan Kalimantan. Perubahan iklim mengakibatkan musim kemarau memanjang di sebagian besar wilayah Jawa, bagian selatan Sumatera, Kalimantan Tengah, Sulawesi Selatan, dan Nusa tenggara (Rejekiningkrum et al., 2011).

Curah hujan pada musim hujan lebih bervariasi dibandingkan dengan musim kemarau (Boer et al., 2009). Perubahan pola hujan yang sudah terjadi beberapa dekade terakhir meliputi pergeseran awal musim hujan, perubahan pola curah hujan, dan peningkatan kejadian iklim ekstrim. Hal ini dapat menurunkan kemampuan tanaman untuk beradaptasi atau menjalankan fungsi fisiologis dan perkembangan, pertumbuhan dan produksi secara optimal (Rejekiningkrum et al., 2011).

Sentra produksi padi yang sudah menerapkan IP 300 atau IP 200 terpaksa menurunkan intensitas penanaman. Wilayah yang menerapkan IP 100 seperti lahan pesisir dan pasang surut pada umumnya kesulitan meningkatkan IP karena terjadi cekaman lingkungan setelah musim tanam reguler.

Salah satu cara yang dapat dilakukan untuk menghemat waktu adalah mensiasati musim dengan menggunakan sistem ratun atau salibu. Ratun atau salibu adalah tanaman yang tumbuh dari tunggul sisa pemotongan pada saat panen. Perbedaan keduanya adalah pada perlakuan tunggul sisa panen. Pada sistem ratun, tidak ada pemotongan tunggul lagi setelah panen. Pada sistem salibu, tunggul dibiarkan selama 7 hari dan setelah tunas mulai tumbuh, tunggul dipotong rendah setinggi $3 \mathrm{~cm}$ dari permukaan tanah. Dengan demikian terdapat perbedaan diantara ratun dan salib yaitu tinggi pemotongan dan intensitas pemotongan batang.

Genotipe memiliki respon yang berbeda terhadap tinggi pemotongan. Tinggi pemotongan $10 \mathrm{~cm}$ di atas permukaan tanah sesuai untuk galur PTB IPB106-7-47-DJ-1 dan IPB106-F-8-1, sedangkan tinggi pemotongan 20 $\mathrm{cm}$ dari permukaan tanah ideal untuk varietas
PTB Cimelati, hibrida Hipa-5 dan Rokan (Susilawati et al., 2012). Tinggi pemotongan 5 $\mathrm{cm}$ dari permukaan tanah, dapat menurunkan hasil $12-37 \%$ dibandingkan tinggi pemotongan $15 \mathrm{~cm}$ (Santos et al, 2003). Pemotongan yang rendah mempercepat keluarnya tunas ratun (Rong et al., 2009) dan dapat memperpanjang umur ratun hingga 4 hari (Vergara et al., 1988). Pemotongan yang lebih rendah dari $20 \mathrm{~cm}$ mengakibatkan tunas atau anakan ratun banyak mengalami kebusukan karena tergenang air (Calendacion et al., 1992). Tinggi pemotongan yang pendek atau hanya beberapa $\mathrm{cm}$ di atas permukaan tanah memberikan hasil ratun yang lebih rendah. Mengurangi tinggi pemotongan akan menyebabkan umur panen lebih panjang (Begum et al., 2002).

Teknologi padi salibu dapat menghemat waktu pertanaman sekitar 40 hari dibanding dengan tanam pindah (Abdulrachman et al., 2015). Di sisi lain, pemotongan rendah di lahan pasang surut dapat menyebabkan banyak rumpun hilang. Pada sistem ratun, Sinaga et al. (2015) melaporkan bahwa pemotongan setinggi $3 \mathrm{~cm}$ atau hanya tersisa 1 buku, menyebabkan $96 \%$ rumpun hilang dari populasi. Diduga sistem salibu dapat mengurangi jumlah rumpun hilang sehingga hasil panen dapat meningkat. Untuk itu dilakukan penelitian yang bertujuan untuk mengetahui respon galur-galur padi pada sistem budidaya ratun dan salibu di lahan pasang surut tipe $\mathrm{C}$.

\section{METODOLOGI PENELITIAN}

Penelitian dilaksanakan di Desa Sungai Solok Kecamatan Kuala Kampar, Kabupaten Pelalawan, Riau pada bulan Juli-Oktober 2014 dan di Desa Petak Batuah Kecamatan Kapuas Murung, Kabupaten Kapuas, Provinsi Kalimantan Tengah pada bulan Desember 2012-Agustus 2013. Lokasi di Desa Sungai Solok merupakan lahan pasang surut tipe C dengan jenis tanah bergambut. Lokasi penelitian lebih rendah dari lokasi di sekitarnya sehingga cukup basah selama musim tanam. Lokasi di Desa Petak Batuah merupakan lahan pasang surut tipe $\mathrm{C}$ jenis tanah sulfat masam yang airnya dapat dikendalikan.

Materi genetik yang diuji adalah delapan galur hasil perbaikan kultivar lokal Kabupaten Pelalawan dan dua pembanding yaitu Inpara 2 dan Batang Piaman. Penelitian terdiri dari dua set yaitu percobaan sistem ratun dan salibu. 
Galur dan varietas pada masing-masing set ditanam menggunakan rancangan acak kelompok lengkap dengan ulangan tiga kali. Teknik budidaya ratun dan salibu, adalah:

\section{Tanaman Utama}

Teknik budidaya tanaman utama adalah:

1. Benih dipilih yang bernas dengan merendam benih dalam air dan membuang benih yang mengapung. Benih direndam selama 24 jam lalu diinkubasi 24 jam. Benih disemai dengan kerapatan $25 \mathrm{~g} \mathrm{~m}^{-2}$.

2. Pindah tanam dilaksanakan 18 hari setelah semai (hss) dengan menanam bibit dua batang per lubang tanam pada jarak tanam 20 $\mathrm{cm}$ x $20 \mathrm{~cm}$. Pemeliharaan yang dilakukan selama musim tanam adalah pengairan, pemupukan, pengendalian hama dan penyakit, dan penyiangan.

3. Pupuk diberikan dua kali, yaitu pada saat tanam dan 35 hari setelah tanam dengan cara tebar. Pada saat tanam diberikan $100 \mathrm{~kg} \mathrm{ha}^{-1}$ Urea, $100 \mathrm{~kg} \mathrm{ha}^{-1} \mathrm{SP} 36$, dan $50 \mathrm{~kg} \mathrm{ha}^{-1} \mathrm{KCl}$. Pada umur 35 hss, tanaman dipupuk dengan $100 \mathrm{~kg} \mathrm{ha}^{-1}$ Urea dan $25 \mathrm{~kg} \mathrm{ha}^{-1} \mathrm{KCl}$.

4. Panen tanaman utama ratun dan salibu dilakukan secara manual dengan sabit pada saat masak fisiologis (bulir berwarna kuning 95\%) dan batang masih hijau. Pemotongan dilakukan pada ketinggian $25 \mathrm{~cm}$ dari permukaan tanah. Dua minggu sebelum dan setelah panen, lahan dibiarkan dalam kondisi lembab atau kapasitas lapang.

\section{Tanaman Ratun}

Tujuh hari setelah panen tanaman utama, lahan diairi setinggi $3 \mathrm{~cm}$ dan ditaburkan Urea $100 \mathrm{~kg} \mathrm{ha}^{-1}$.

\section{Tanaman Salibu}

Sisa batang atau tunggul yang disisakan sekitar $25 \mathrm{~cm}$ dari permukaan tanah pada saat panen, dibiarkan selama 7 hari hingga keluar tunas baru. Selanjutnya dilakukan pemotongan ulang tunggul sisa panen secara seragam dengan alat pemotong hingga tersisa $3 \mathrm{~cm}$ dari permukaan tanah. Alat pemotong yang digunakan adalah alat mesin pemotong rumput bermata pisau petak. Setelah tunas salibu keluar, lahan diairi setinggi $3 \mathrm{~cm}$ dari permukaan tanah. Penyulaman dilakukan dengan memecah rumpun-rumpun salibu lalu disulamkan ke lokasi tanaman yang tidak tumbuh.

Pemupukan dilakukan secara tabur pada kondisi air macak-macak, pemupukan pertama diberikan sebanyak $40 \mathrm{~kg} \mathrm{ha}^{-1}$ Urea pada saat tanaman salibu berumur antara 15 hari setelah panen (hsp). Pemupukan kedua diberikan sebanyak $60 \mathrm{~kg} \mathrm{ha}^{-1}$ Urea pada saat tanaman berumur $35 \mathrm{hsp}$.

Data diolah menggunakan analisis varians (anova) dan dilanjutkan dengan uji Tukey untuk melihat perbedaan antar perlakuan. Variabel yang diamati pada tanaman utama, ratun, dan salibu adalah tinggi tanaman, jumlah anakan produktif, umur panen jumlah biji bernas per malai, bobot 1000 butir, dan hasil panen.

\section{HASIL DAN PEMBAHASAN}

Selama penelitian berlangsung, lahan percobaan memperoleh cukup air dan genangan tidak kurang dari $10 \mathrm{~cm}$ (Tabel 1). Tanaman utama pada kedua metode ratun dan salibu tumbuh baik. Tidak ditemukan serangan hama maupun penyakit yang berarti.

Tabel 1. Ketinggian Air dan Lama Genangan Selama Pertanaman di Desa Sungai Solok, Riau dan Desa Petak Batuah, Kalimantan Tengah.

\begin{tabular}{ccc}
\hline \multirow{2}{*}{ Umur tanaman (minggu) } & \multicolumn{2}{c}{ Tinggi genangan $(\mathrm{cm})$} \\
\cline { 2 - 3 } & Sungai Solok & 0 \\
2 & 10 & 3 \\
3 & 11 & 3 \\
4 & 14 & 4 \\
5 & 14 & 0 \\
6 & 23 & 0 \\
7 & 25 & 5 \\
8 & 22 & 5 \\
9 & 29 & 8 \\
10 & 27 & 0 \\
11 & 32 & 3 \\
12 & 24 & 2 \\
13 & 25 & 0 \\
14 & 19 & 0 \\
\hline
\end{tabular}


Hasil penelitian menunjukkan bahwa daya hasil masing-masing galur bervariasi (Tabel 2). Enam galur secara konsisten memberikan hasil lebih tinggi dari $7 \mathrm{t} \mathrm{ha}^{-1} \mathrm{GKG}$ dari tanaman utama pada percobaan ratun dan salibu. Galur P1F-B-A15, P1D-KK-A26, P17EB-A48, P1D-KK-A48b, P5E-KK-A5 memberikan hasil ratun yang tinggi sehingga total hasil tanaman utama + ratun juga tinggi. Galur-galur yang berdaya hasil tinggi pada tanaman utama dan ratun merupakan galur yang diharapkan.
Respon galur/varietas berbeda terhadap metode ratun dan salibu. Galur pada perlakuan metode ratun menghasilkan anakan ratun yang tumbuh baik dan hasil panen bervarisi, sedangkan galur pada metode salibu tidak memberikan hasil. Sebagian besar tunas ratun tumbuh pada buku lebih dari $5 \mathrm{~cm}$ di atas permukaan tanah dan hanya sedikit yang tumbuh dari permukaan tanah. Perubahan posisi tumbuh tunas ratun berhubungan dengan genangan air yang cukup lama dan tinggi.

Tabel 2. Daya Hasil Tanaman Utama, Ratun, dan Salibu Galur-Galur Harapan di Lahan Pasang Surut Tipe C yang Tergenang Selama Musim Tanam.

\begin{tabular}{|c|c|c|c|c|c|c|}
\hline \multirow[b]{2}{*}{ Galur/varietas } & \multicolumn{4}{|c|}{ Metode ratun } & \multicolumn{2}{|c|}{ Metode salibu } \\
\hline & $\begin{array}{l}\text { Tanaman utama } \\
\text { (TU) }\end{array}$ & Ratun (R) & TUt & & $\begin{array}{l}\text { Tanaman utama } \\
\text { (TU) }\end{array}$ & Salibu \\
\hline P1F-KK-A1 & 5,39 & 3,04 & 8,43 & $\mathrm{Bc}$ & 5,5 & 0 \\
\hline P1F-B-A7 & 6,53 & 2,75 & 9,28 & $\mathrm{Abc}$ & 5,1 & 0 \\
\hline P1F-B-A15 & 7,49 & 4,23 & 11,72 & $\mathrm{Ab}$ & 8,2 & 0 \\
\hline P1D-KK-A26 & 7,25 & 3,73 & 10,98 & $\mathrm{Abc}$ & 8,8 & 0 \\
\hline P1D-KK-A45 & 7,02 & 1,92 & 8,94 & $\mathrm{Abc}$ & 8,4 & 0 \\
\hline P17E-B-A48 & 6,53 & 3,73 & 10,26 & $\mathrm{Abc}$ & 6,5 & 0 \\
\hline P1D-KK-A48b & 6,51 & 5,00 & 11,51 & $\mathrm{Ab}$ & 6,5 & 0 \\
\hline Inpara 2 & 5,46 & 4,92 & 10,38 & $\mathrm{Abc}$ & 7,3 & 0 \\
\hline Btg Piaman & 5,58 & 2,54 & 8,12 & $\mathrm{C}$ & 6,8 & 0 \\
\hline P1D-KK-A67 & 7,19 & 2,46 & 9,65 & $\mathrm{Abc}$ & 8,3 & 0 \\
\hline P5E-KK-A5 & 7,38 & 4,75 & 12,13 & A & 7,5 & 0 \\
\hline P253F-B-53 & 7,27 & 2,48 & 9,75 & $\mathrm{Abc}$ & 7,8 & 0 \\
\hline
\end{tabular}

Keterangan: Angka yang diikuti huruf kecil yang sama pada kolom yang sama berarti berbeda tidak nyata menurut uji Tukey .05.

Tingkat kelulusan hidup batang tanaman utama pada percobaan ratun maupun salibu setelah pemotongan setinggi $25 \mathrm{~cm}$ rata-rata 95\%. Sebagian besar rumpun menghasilkan tunas tujuh hari setelah panen. Pada hari ke-14 setelah perlakuan, tunas ratun tumbuh dengan baik sedangkan tunas salibu tidak tumbuh. Pemotongan tahap kedua pada metode salibu telah menghilangkan semua tunas. Setelah diamati dari ratun, ternyata rata-rata tunas tumbuh pada buku yang lebih tinggi dari $5 \mathrm{~cm}$ di permukaan tanah. Dengan demikian pemotongan pada metode salibu dengan menyisakan $3 \mathrm{~cm}$ batang tidak memiliki bakal tunas yang viabel karena semua mati selama penggenangan.

Pemotongan tunggul yang lebih rendah pada percobaan salibu tidak menyisakan tunas viabel sehingga tidak ada rumpun yang tumbuh kembali . Batang padi yang tergenang lama telah mengubah regulasi fisiologis dengan mengaktifkan tunas-tunas pada buku yang lebih tinggi dan mematikan tunas-tunas yang tergenang air. Diduga air yang berwarna keruh juga berperan menonaktifkan tunas-tunas yang lebih rendah dengan menghalangi sinar matahari. Menurut Harrell et al. (2009), menurunkan tinggi pemotongan tanaman utama pada saat panen diyakini mengubah parameter pertumbuhan dan hasil salibu. Menurut Huossainzade et al. (2011), tinggi pemotongan berpengaruh nyata terhadap hasil dan jumlah anakan produktif padi yang tumbuh dari tunggul sisa pemotongan.

Kondisi lingkungan selama musim tanam sangat berpengaruh terhadap viabilitas tunastunas anakan pada batang sisa panen. Pada percobaan di lahan pasang surut tipe $\mathrm{C}$ sulfat 
masam yang tidak pernah tergenang lama di Desa Petak Batuah, perlakuan salibu memberikan hasil yang cukup baik (Tabel 3). Satu minggu setelah panen, tunas-tunas salibu sudah tumbuh baik dari buku permukaan tanah maupun dari buku di atas permukaan tanah. Persentase rumpun hidup satu minggu setelah panen tanaman utama cukup tinggi.
Budidaya salibu membutuhkan kondisi lingkungan bukan daerah endemik tungro, busuk batang, hawar daun bakteri, maupun keong mas, serta tidak terjadi genangan atau kekeringan yang lama (BB Padi, 2015).

Tabel 3. Daya Hasil Tanaman Utama dan Salibu Galur-Galur Harapan di Lahan Pasang Surut Tipe C Desa Petak Batuah, Kabupaten Kapuas, Provinsi Kalimantan Tengah.

\begin{tabular}{|c|c|c|c|c|c|c|c|c|}
\hline \multirow{2}{*}{$\begin{array}{l}\text { Galur/Varieta } \\
\text { P1F-KK-A1 }\end{array}$} & \multicolumn{2}{|c|}{$\begin{array}{l}\text { Hasil Tanaman Utama (TU) } \\
\qquad\left(\mathrm{t} \mathrm{ha}^{-1} \mathrm{GKG}\right)\end{array}$} & \multicolumn{2}{|c|}{$\begin{array}{l}\text { Hasil Salibu (S) } \\
\left(\mathrm{t} \mathrm{ha}^{-1} \mathrm{GKG}\right)\end{array}$} & \multicolumn{2}{|c|}{$\begin{array}{l}\text { Hasil TU+S } \\
\left(\mathrm{t} \mathrm{ha}^{-1} \mathrm{GKG}\right)\end{array}$} & \multirow{2}{*}{$\begin{array}{c}\begin{array}{c}\text { Rumpun } \\
\text { Hidup } \\
\text { Ratun } \\
(\%)\end{array} \\
85,7\end{array}$} & \multirow{2}{*}{$\begin{array}{c}\begin{array}{c}\text { Rumpun } \\
\text { Hidup } \\
\text { Salibu } \\
(\%)\end{array} \\
78,6\end{array}$} \\
\hline & 4,57 & $\mathrm{~cd}$ & 3,17 & $\mathrm{a}$ & 7,73 & $\mathrm{ab}$ & & \\
\hline P1F-B-A7 & 5,07 & bcd & 3,60 & $\mathrm{a}$ & 8,67 & $\mathrm{ab}$ & 79,2 & 76,5 \\
\hline P1F-B-A15 & 5,60 & $a b c$ & 3,87 & $\mathrm{a}$ & 9,47 & $\mathrm{a}$ & 89,7 & 86,1 \\
\hline P1D-KK-A26 & 5,13 & bcd & 4,07 & $\mathrm{a}$ & 9,20 & $\mathrm{a}$ & 94,9 & 88,5 \\
\hline P1D-KK-A45 & 5,27 & $a-d$ & 3,63 & $\mathrm{a}$ & 8,90 & $\mathrm{ab}$ & 91,8 & 83,8 \\
\hline P17E-B-A48 & 5,20 & bcd & 3,00 & $\mathrm{a}$ & 8,20 & $\mathrm{ab}$ & 82,9 & 79,7 \\
\hline P1D-KK-A48b & 4,93 & bcd & 4,40 & $\mathrm{a}$ & 9,33 & $\mathrm{a}$ & 95,7 & 87,4 \\
\hline Inpara 2 & 5,23 & $a-d$ & 2,70 & $\mathrm{a}$ & 7,93 & $\mathrm{ab}$ & 84,2 & 82,1 \\
\hline Btg Piaman & 3,90 & $\mathrm{~d}$ & 2,63 & $\mathrm{a}$ & 6,53 & $\mathrm{~b}$ & 81,2 & 78,3 \\
\hline P1D-KK-A67 & 6,23 & $\mathrm{ab}$ & 3,47 & $\mathrm{a}$ & 9,70 & $\mathrm{a}$ & 90,6 & 83,9 \\
\hline P5E-KK-A5 & 5,77 & $a b c$ & 4,40 & $\mathrm{a}$ & 10,17 & $\mathrm{a}$ & 93,1 & 87,7 \\
\hline P253F-B-53 & 6,80 & $\mathrm{~A}$ & 3,17 & $\mathrm{a}$ & 9,97 & $\mathrm{a}$ & 85,1 & 79,1 \\
\hline
\end{tabular}

Keterangan: Angka yang diikuti huruf kecil yang sama pada kolom yang sama berarti berbeda tidak nyata menurut uji Tukey .05.

Terjadi penurunan jumlah rumpun hidup pada setiap pemotongan batang tanaman. Pada pemotongan tahap pertama atau pada tahap ratun, rata-rata jumlah rumpun hidup ratun sebesar $87,8 \%$ dan turun menjadi $82,6 \%$ pada tahap salibu. Rumpun hidup ratun adalah rumpun yang mampu menumbuhkan tunas satu minggu setelah panen tanaman utama dengan tinggi pemotongan $25 \mathrm{~cm}$ di atas permukaan tanah. Rumpun hidup salibu adalah rumpun yang mampu menumbuhkan tunas satu minggu setelah rumpun ratun dipotong lagi setinggi 3 $\mathrm{cm}$ dari permukaan tanah. Penurunan rumpun hidup pada tahap salibu disebabkan oleh rumpun-rumpun tahap ratun yang tidak menumbuhkan tunas dari permukaan tanah. Penurunan jumlah rumpun hidup dari ratun ke salibu berkisar 2,1-8,3\% dan sebagian besar diantaranya adalah rumpun yang menumbuhkan tunas pada buku yang lebih tinggi dari $5 \mathrm{~cm}$ dari permukaan tanah.
Galur P1F-B-A15, P1D-KK-A26, P1DKK-A45，P1D-KK-A48b，P1D-KK-A67， dan P5E-KK-A5 menunjukkan respon yang baik terhadap perlakuan ratun maupun salibu. Pada kedua perlakuan tersebut, jumlah rumpun hidup yang cukup tinggi berpengaruh terhadap tingginya hasil panen salibu. Tingginya hasil panen tersebut sebagai akibat dari pertumbuhan yang baik yang ditunjukkan oleh tingginya jumlah anakan dan panjangnya umur panen dibandingkan pada perlakuan ratun. Tanaman ratun sudah dapat dipanen pada umur 60-70 hari tetapi salibu dapat dipanen pada umur 8090 hari. Pengaruh genotipe sangat penting dalam menentukan umur panen ratun maupun salibu. Kelebihan salibu dibandingkan ratun adalah asal tumbuh anakan yang sama-sama dari pangkal batang di permukaan tanah. Anakan yang telah tumbuh pada tahap ratun segera membentuk anakan baru lagi beberapa hari setelah pemotongan rendah pada tahap salibu. Asal-usul anakan dari pangkal batang menyebabkan tunas yang tumbuh mirip dengan 
tanaman utama, batang besar, tinggi tanaman seragam, umur lebih panjang sehingga pengisian bulir lebih sempurna, dan hasil lebih tinggi. Tingginya jumlah tunas yang tumbuh beberapa hari setelah pemotongan tahap salibu, mirip dengan fenomena pemutusan dominansi apikal yang memacu pertumbuhan tunas lateral. Hal inilah yang menyebabkan anakan pada salibu lebih banyak.

Galur P1D-KK-A26, P1D-KK-A48b, dan P5E-KK-A5 memberikan hasil salibu masingmasing 79, 89, 76\% dari tanaman utama. Galurgalur tersebut potensial dijadikan sebagai padi salibu pada lahan sawah yang airnya dapat dikontrol atau tidak selalu tergenang. Tingginya hasil salibu merupakan kontribusi jumlah rumpun hidup yang tinggi. Perlu memperhatikan viabilitas tunas-tunas salibu untuk menentukan satu galur menjadi padi salibu. Ketiga galur di atas memiliki persentase rumpun hidup yang tinggi. Kemampuan menumbuhkan tunas pada batang bersifat genetik dan dipengaruhi lingkungan. Kondisi agroekosistem yang lebih baik di sawah irigasi diduga dapat meningkatkan jumlah rumpun hidup dan anakan padi salibu.

Namun panjangnya umur panen salibu dibandingkan ratun dan hasil panen yang tidak melebihi hasil tanaman utama menyebabkan metode salibu hanya dapat diterapkan di sawahsawah pasang surut yang indeks pertanamannya 100. Pada lahan sawah yang sudah menerapkan IP 200 dan menggunakan varietas unggul, metode salibu dapat mengganggu musim tanam berikutnya.

\section{KESIMPULAN}

Budidaya padi salibu di lahan pasang surut yang tergenang tidak memberikan hasil sedangkan di lahan tipe c yang airnya dapat diatur, galur P1D-KK-A26, P1D-KK-A48b, dan P5E-KK-A5 memberikan hasil salibu lebih dari $4 \mathrm{t} \mathrm{ha}^{-1}$ GKG. Budidaya padi ratun dapat dilakukan di lahan yang tergenang maupun yang airnya dapat diatur. Galur P1F-B-A15, P1D-KK-A26, P1D-KK-A45, P1D-KK-A48b, P1D-KK-A67, dan P5E-KK-A5 dapat dibudidayakan secara ratun maupun salibu. Upaya mensiasati penyempitan musim tanam dengan teknik budidaya ratun dapat dilaksanakan pada lahan pasang surut yang kering maupun tergenang, sedangkan teknik salibu baik dilaksanakan di lahan yang tidak selalu tergenang.

\section{DAFTAR PUSTAKA}

Abdulrachman, S., Suhartatik, E., Erdiman, Susilawati, Zaini, Z., Jamil, A., Mejaya, M.J., Sasmita, P., Abdulah, B., Suwarno, Baliadi, Y., Dhalimi, A., Sujinah, Suharna, Ningrum, E.S. 2015. Panduan Teknologi Budidaya Padi Salibu. Badan Penelitian dan Pengembangan Pertanian. 17 hal. ISBN 978-979-540-096-7.

BB Padi. 2016. Agroekosistem Lahan Untuk Budidaya Padi Salibu. http://bbpadi.litbang.pertanian.go.id/inde x.php/berita/berita-utama/content/ 126agroekosistem-lahan-untuk-budidayapadi-salibu. Diunduh 22 Mei 2016.

Begum, M.K., Hasan, K.M., Hossain, S.M.A., Hossain, M.A. 2002. Effect of culm cutting height and nitrogenous fertilization on the yield on ratoon late Boro rice. J. Agron., 1:136-138. Boer, R., Buono, A., Sumaryanto, Surmaini, E., Rakhman, A., Estiningtyas, W., Kartikasari, K., and Fitriyani. 2009. Agriculture Sector. Technical Report on Vulnerability and Adaptation Assessment to Climate Change for Indonesia's Second National Communication. Ministry of Environment and United Nations Development Programme, Jakarta.

Calendacion, A.N., Garrity, D.P., Ingram, K.T.. 1992. Locklodging: a new technology for ratoon rice crop. Philippine J. Crop Sci., 17:1-10.

Harrell, D.L., Bond, J.A., Blanche, S. 2009. Evaluation of main crop stubble height on ratoon rice growth and development. Field Crops Res., 114: 396-403.

Huossainzade, A., Azarpour, E., Doustan, H.Z., Moraditochaee. M., Bozorgi, H.R. 2011. Management of cutting height and nitrogen fertilizer rates on grain yield and several attributes of ratoon rice (Oryza sativa L.) in Iran. World App Sci J., 15 (8):1089-1094.

Rong. Z., Xiao-ping, L., Shang, Z., Chuan-ying, Z., Zhaowei, J. 2009. Growth characteristics of stem axiliary buds on ratoon rice. Fujian J. Agric. Sci., 3:21-34. 
Santos, A.B., Fageria, N.K., Prabhu, A.S. 2003. Rice ratooning management practices for higher yields. Commun. Soil Sci. Plant Anal., 34:881-918. I

Susilawati, Purwoko, B.S., Aswidinnoor, H., Santosa, E. 2012. Tingkat produksi ratun berdasarkan tinggi pemotongan batang padi sawah saat panen. J. Agron. Indonesia, $40(1): 1-7$.

Vergara, B.S., Lopez, F.S., Chauhan, J.S. 1988. Morphology and physiology of ratoon rice. p. 31-40. In W.H. Smith, V. Kumble, E.P. Cervantes (Eds.) Rice Ratooning. IRRI, Los Banos, Philippines. 
